\title{
$\beta$-galactosidase and Annexin V/PI Assays as QC Tests for Manufacturing cGMP-Grade Wharton Jelly Derived Mesenchymal Stem Cells
}

\author{
Gulnaz Yildirim Koken \\ Center for Regenerative Medicine and Stem Cell Research \\ $\&$ Manufacturing (LivMedCell), Istanbul, Turkey \\ Yildiz Technical University, Department of Bioengineering, Istanbul, Turkey \\ E-mail: gulnazyildirim88@gmail.com \\ Olga Nehir Oztel \\ Center for Regenerative Medicine and Stem Cell Research \\ \& Manufacturing (LivMedCell), Istanbul, Turkey \\ Istinye University, Vocational School of Health, Istanbul, Turkey \\ Cansu Subasi Demir \\ Center for Regenerative Medicine and Stem Cell Research \\ \& Manufacturing (LivMedCell), Istanbul, Turkey \\ Erdal Karaoz (Corresponding author) \\ Center for Regenerative Medicine and Stem Cell Research \\ $\&$ Manufacturing (LivMedCell), Istanbul, Turkey \\ Istinye University, Center for Stem Cell and Tissue Engineering Research \& Practice, Istanbul, Turkey \\ Istinye University, Faculty of Medicine, Department of Histology \& Embryology, Istanbul, Turkey \\ Istinye University, Department of Medical Laboratory Techniques, Istanbul, Turkey
}

\begin{abstract}
Background: According to the guidelines for cGMP, strictly regulated procedures and quality control (QC) tests are required. However, none of the regulations by authorities suggested have $\beta$-galactosidase and Annexin V/PI assays as QC tests. In this study, we aimed to demonstrate the feasibility of Annexin $\mathrm{V}$ and $\beta$-galactosidase assays as valid cGMP-compliant QC tests.
\end{abstract}

Methods: Wharton's Jelly derived mesenchymal stem cells (WJ-MSCs) were isolated, characterized and screened as valid QC tests. In this study, in addition to routine QC tests, $\beta$-gal assays were performed to confirm telomerase activity and Annexin V methods were used to confirm cell viability assays.

Results: It was concluded that one donor (WJ-MSC-3) has higher telomerase activity and it has lowest $\beta$-gal activity at the same time $(p<0,001)$. Only one donor showed significant difference in annexin $\mathrm{V}$ viability tests, indicating the importance of using automatic devices and Annexin $\mathrm{V}$ to manual tests for cell viability analysis (Muse: 92,48 $\pm 0,487 \%$ Flow Cytometry: $90,76 \pm 1,116 \% \mathrm{p}<0,01$ ).

Conclusion: With these existing data, telomerase activity and senescence levels may correlate and affect MSC quality in cell based therapy. In order to determine the viability values by adding Annexin $\mathrm{V}$ based automated methods could give more guaranteed results.

Key words: Good Manufacturing Practice, SA-b-galactosidase, cell senescence, telomerase activity, Annexin V, cell based medicinal products.

DOI: $10.7176 / \mathrm{JSTR} / 6-12-07$

64 | P a g e

www.iiste.org 


\section{Introduction}

Mesenchymal stem cells (MSCs) isolated from different sources are promising therapeutic elements used in cellular therapy procedures $[1,2]$. Human MSCs (hMSCs) are commonly used in clinical cell transplantation studies, because of these cells have anti-inflammatory, anti-apoptotic, anti-angiogenic, regenerative and immunomodulatory abilities $[1,3,4]$. There are more than 500 studies about the safety and efficacy of MSCs in the clinical trials [5].

MSCs can be isolated from placenta and its derivatives, such as amniotic membrane, amniotic fluid, chorionic villi, umbilical cord blood and Wharton's Jelly (WJ). MSCs are abundant in WJ and it is the most preferred stem cell source because of its immunogenicity-lowering effect, high telomerase level and high level of HLA-G [6-10]. This expression profile, helps to the fetus for avoid from the attack of the immune system of mother against it during pregnancy and improves graft acceptance [11]. High expression of HLA-G in WJ-MSCs, makes these cells ideal for third-party/allogeneic applications in neurodegenerative disease in clinical trials [12-14]. Furthermore, WJ-MSCs are thought to preserve immature phenotypes in ex vivo cultures, due to sustained telomerase activity in later passages[10]. It has been demonstrated that WJ-MSCs can proliferate and differentiate in culture medium for a long time without showing genetic instability or oncogenicity [15].

Existing current Good Manufacturing Practice (cGMP) principles ensure certain procedures for preparation, manufacturing, processing, packaging and quality control of final product for clinical applications $[16,17]$. cGMP guidelines strictly regulate the procedures and quality control measures for manipulation of stem cells as "medicinal products" and aim to make safer and more successful engraftments [18]. Many highly standardized microbiological, immunophenotypic, and genetic quality control tests are in compliance with GMP $[19,20]$.

hMSCs are present in several tissues but they are scarce in the body [21]. For successful cell therapy and fulfill the need of hundreds of millions of hMSCs per treatment, an extensive ex vivo cell expansion is required. However, hMSC proliferation is limited and it is likely that long-term culture may cause continuous changes in MSCs, a significant amount of cells may undergo senescence [21, 22].

Detection of stem cell senescence and viability are also critical for successful cellular therapy [23, 24]. However none of the regulations by authorities suggested have senescence associated $\beta$-galactosidase (SA-b-gal or $\beta$-Gal) and Annexin V/PI staining as quality control tests [25-28]. Annexin V is a Ca $2^{+}$dependent phospholipid binding protein with high affinity to phosphotidylserine. Membrane integrity is impaired in apoptotic cells, so that Annexin V spreads into the cell and stains phosphotidylserine molecules [29].

In the current study, we aim to investigate the quality controls test results of the WJ-MSCs carried out as described in related standard operation procedures (SOPs) of the Center for Regenerative Medicine and Stem Cell Research \& Manufacturing (LivMedCell) in Liv Hospital, Istanbul, Turkey, and also demonstrate the results of both Annexin V (using two devices) and senescence tests and we want to offer these tests as a valid cGMP quality control tests.It is important to increase the quality of cells in order to achieve high yield in clinical trials.For improving cell quality, $\beta$-gal tests were studied to confirm telomerase activity and Annexin $\mathrm{V}$ methods were performed to confirm cell viability assays in addition to routine $\mathrm{QC}$ tests.

\section{Materials and Methods}

\subsection{Cell Processing (Isolation, Culture, and Characterizations of WJ-MSCs)}

Human umbilical cord tissue samples were obtained from 4 healthy donors with their written informed consent. Under sterile conditions, each umbilical cord unit was manipulated. Isolation protocols were performed in parallel for all of WJs. Briefly, cord units were cut into sections about $5 \mathrm{~cm}$. Pieces were washed with DPBS solution to remove blood. For prevention from endothelial cell contamination, arteries and vein were removed. Then, WJ pieces were cut into smaller pieces and these pieces were adhered in $100 \mathrm{~mm}^{2}$ cell culture plates. They were cultured in MSC NutriStem $\AA$ XF Basal Medium and MSC NutriStem ${ }^{\circledR}$ XF Supplement Mix (Biological Industries, Cromwell, CT, USA) cell culture media supplied with $2 \%$ human serum (Seracare, Milford, MA, US) and $50 \mathrm{U} / \mathrm{ml}$ penicilin-streptomycin (Biological Industries, Cromwell, CT, USA). Cells were grown in a humidified atmosphere containing $5 \% \mathrm{CO}_{2}$ at $37^{\circ} \mathrm{C}$ and have been subcultured until the third passage.

Characterization tests were performed to prove that the isolated cells were human stem cells as routine QC tests in our laboratory. Immunophenotypic and differentiation potential (adipogenic, chondrogenic, osteogenic) assays of MSCs were performed in accordance with our previous studies [30-33].

$65 \mid \mathrm{P}$ a g e 
In order to manufacture the cell based therapy products, flow cytometry analysis, cell viability assessment, mycoplasma detection, gene expression, telomerase activity; endotoxin and sterility tests were performed mentioned below as "Valid Quality Control Tests".

\subsection{Valid Quality Control Tests}

Certain QC tests of medicinal products must be performed before applying to the patient.These tests determine whether the cells are suitable for application to the patient or not. They also help scientists to improve the quality of cells and thus the success rate of treatments might be increase. Manufacturing and quality control tests of WJ-MSCs have been performed in a cGMP cell production facility; LivMedCell, authorized by the Ministry of Health of Turkey with the cGMP license rules.

\subsection{Flow cytometry analysis}

The immunophenotype of cultured WJ-MSCs were determined by FACSCalibur with the human MSCs analysis kit hMSC positive cocktail (FITC-CD90, PerCP-cy5.5-CD105, and APC-CD73), and the PEhMSC Negative Cocktail (CD11b, CD19, CD34, CD45, and HLA-DR) (BD Biosciences) [1, 16, 34]. All experiments were carried out for 4 times.

\subsection{Cell viability assay}

Cell viability was determined using the Muse Count \& Viability Kit (Merck KGaA, Darmstadt, Germany) and Annexin V dye with muse and flow cytometry device. Viable cells were counted and percentage of cells were analyzed as early apoptotic, apoptotic and necrotic.

Muse Count \& Viability Kit and flow cytometric analysis have almost the same working principles. According to Muse Count \& Viability Kit, a DNA-binding dye stains the nucleus of dead and dying cells that have lost their membrane integrity.In flow cytometry method, Annexin V is used for staining membrane phosphatidyl serine of apoptotic cells that have lost their membrane properties.

\subsection{Mycoplasma detection}

Sensoquest Labcycler and e-Myco Mycoplasma PCR Detection Kit (Intron Biotechnology, US) was used for mycoplasma detection according to manufacturer's instructions.

\subsection{Endotoxin}

Endotoxin levels were analyzed using Cape Cod Pyros Kinetix Flex and Pyrogent 25 Single Test (Lonza) according to the manufacturer's instructions.

\subsection{Sterility Test}

MSC sterility was assessed by Bactalert for 14 days (BacT/Alert ${ }^{\circledR}$ bioMérieux Corporate-Durham, USA).

\subsection{Gene Expression}

Gene expression analyses were performed for characterization of isolated cells as our routine QC tests. Total RNA was isolated from P4 cell cultures (WJ-MSCs) using Qiagen RNA isolation kit and cDNA was synthesized using RT2 First Standard Kit (Qiagen). PCR studies were performed with Syber Green PCR Master Mix. Specific stem cell markers and genes such as ZFP42 (stemness), CD44 (MSC specific marker), POU5F1 (stemness), SOX2 (stemness), VCAM1 (MSC specific marker), NES (Gene associated with MSC), ICAM1 (gene associated with MSC), RUNX2 (osteogenesis, adipogenesis), THY1 (MSC specific marker), TERT (stemness), BMP2 (osteogenesis, chondrogenesis, tenogenesis,MSC specific marker), VIM (gene associated with MSC), LDHA (housekeeping) were performed to analyzed to determine gene expression levelsof WJ-MSCs. In this study GAPDH was selected as the internal control. The cycle threshold $(\mathrm{Ct})$ values are inversely proportional with the amount of nucleic acid in the sample and associated with the number of copies in the sample. If $\mathrm{Ct}$ values are lower than 29, these genes are identified as strong positive genes. If $\mathrm{Ct}$ values are between of 30-37, genes are considered positive according to reactions indicative of moderate amounts of target nucleic acid. In the case of samples between of 38-40, it is possible that there is a weak expression or environmental contamination [35].

\subsection{Telomerase Activity}

Telo TAGGG Telomerase PCR-ELISA Kit (Roche) and conventional telomeric repeat amplification

66 | P a g e

www.iiste.org 
protocol (TRAP) were used for measure to telomerase activity according to the manufacturer's protocol. Briefly, $2 \times 10^{5}$ cells were washed and lysed in ice-cold lysis buffer. Briefly, 2x105 cells were washed and lysed in ice-cold lysis buffer. After the incubation, cell debris was removed and $3 \mathrm{ml}$ of supernatant was incubated with pre-mixed buffer containing biotin-labeled and unlabeled primers, dNTPs and Taq DNA polymerase. Reaction mixture was incubated for $20 \mathrm{~min}$ at $25^{\circ} \mathrm{C}$ [33].

\subsection{Annexin V/PI}

Percentage of apoptotic and viable cells were detected using Annexin V Apoptosis Detection kit on a FACSCalibur flow cytometer, according to the manufacturer's instructions. Cell population analyses were performed using Annexin V-FITC and PI (BD Biosciences, San Diego, CA 92121) staining. Annexin V-FITC and PI stock solutions were added to the sample and incubated for 15 min at room temperature. After the incubation, cells were washed with PBS. A total of 10.000 events were analyzed by BD FACSCalibur and CellQuest Software was used for the analyses.

\subsection{Cellular Senescence Assessment}

Cytochemical staining for SA-b-galactosidase was performed using a Senescence $\beta$-Galactosidase Staining Kit (Cell Signaling Technology, \#9860) at pH 6.0. All the experiments were repeated three times.

\subsection{Statistical Analysis}

Results are presented as mean \pm SEM. GraphPad Prism 5 software was used for statistical analyses. The data was analyzed by one-way analysis of variance (ANOVA) with Tukey's multiple comparison tests. The level of significance was set at $\mathrm{p}<0.05, \mathrm{p}<0.01$ and $\mathrm{p}<0.001$ for all statistical analyses.

\section{Results}

\subsection{Cell Processing (Isolation, Culture, and Characterizations of WJ-MSCs)}

\subsubsection{Differentiation Potential of WJ-MSCs}

Osteogenic, adipogenic and chondrogenic differentiation assays for all WJ-MSC donors were carried out according to our previous study [36]. Oil Red O, Alizarin Red S and Alcian Blue staining protocols were performed for demonstration of adipogenic, osteogenic and chondrogenic differentiation potential respectively. According to our results, all of WJ-MSCs have differentiated into three main lineages which are essential for stem cell characterization analysis (Figure 1).

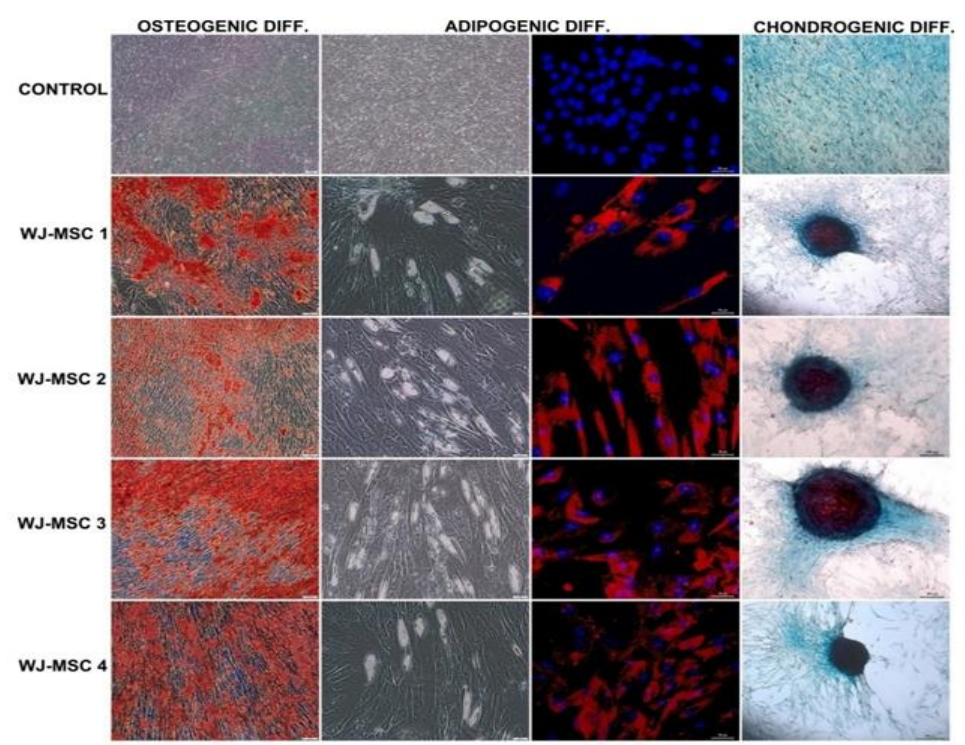

Figure 1: Demonstrate the differentiation of WJ-MKHs into different cell types.

The osteogenic differentiation of all WJ-MSCs was performed by Alizarin red staining. Adipogenic differentiation of all WJ-MSCs was demonstrated by immunofluorescence with oil red (dapi: blue, oil red o: red) and inverted microscope. The chondrogenic differentiation of MSCs was demonstrated by alcian blue staining. 


\subsubsection{Immunofluorescence and Immunohistochemical Characterization of WJ-MSCs}

Our results indicated that all of WJ-MSCs expressed vimentin, CD105, CD44 (Figure 2), nestin, fibronectin (Figure 3), desmin and alpha $(\alpha)$ Smooth Muscle Actin( $\alpha$-SMA) (Figure 3) without stimulation towards differentiation and negative for CD34 and CD45 (hematopoietic markers) (Figure 2).

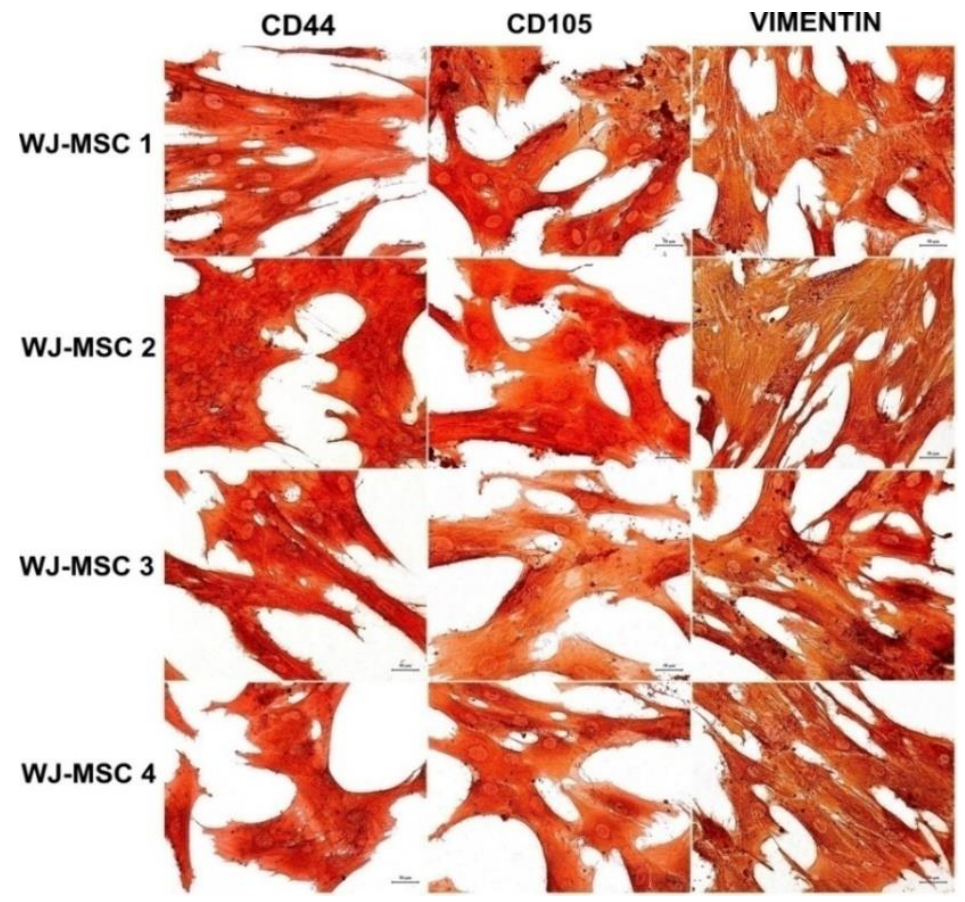

Figure 2: Immunophenotype of cultured WJ-MSCs.

Studies based on immunoperoxidase reactivity were performed with passage 3 cultures of WJ-MSCs. Representative staining patterns are shown for: CD44, CD105 and Vimentin. Nuclei were counterstained with haematoxylin (Scale bars: $50 \mu \mathrm{m})$.

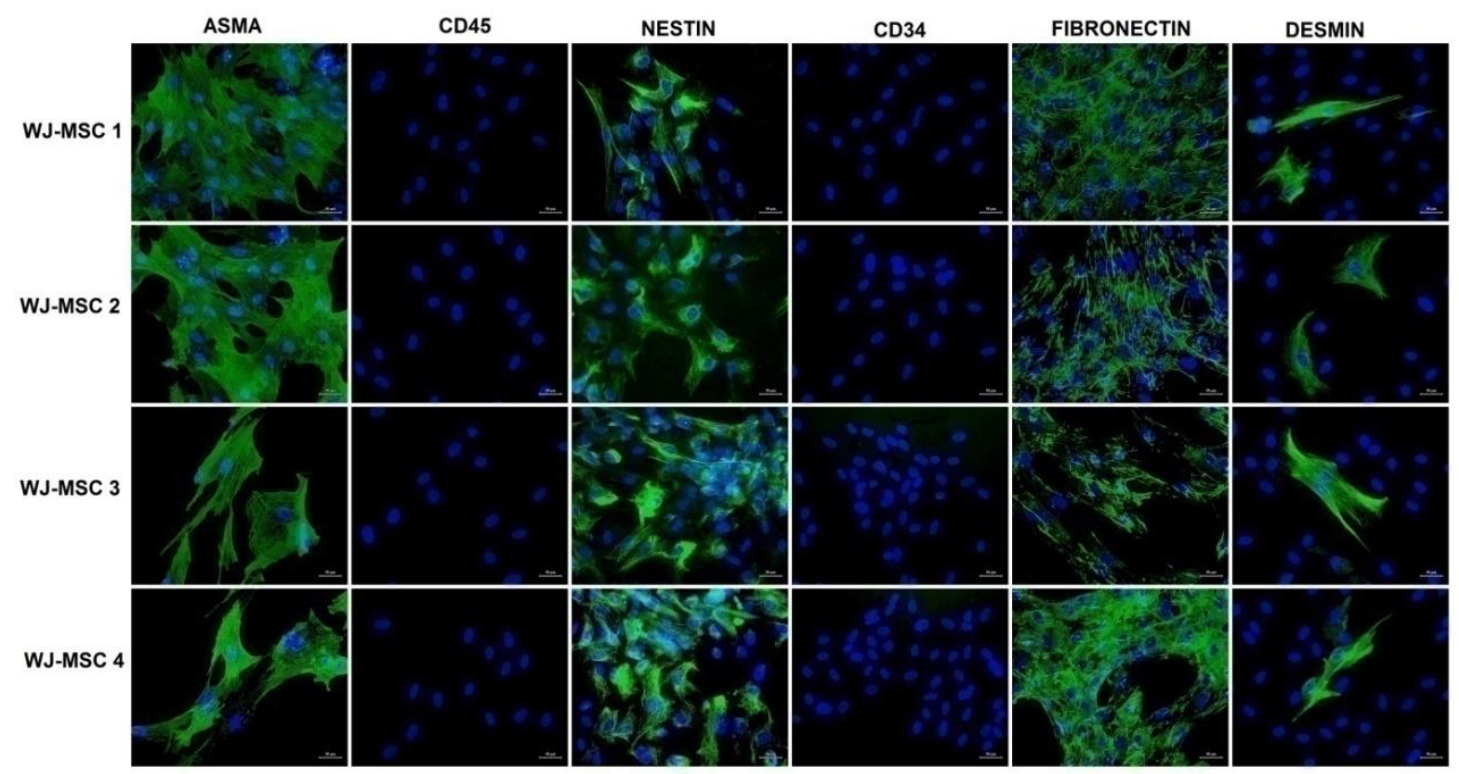

Figure 3: Fluorescence microscopy analysis for expression of cell markers for mesenchymal stem cells characterisation.

Almost all WJ-MSCs expressed fibronectin, a-SMA, nestin and desmin in their cytoplasm. WJ-MSCs did not stain positive with antibody against CD34 and CD45 which are accepted to be hematopoetic markers. Nuclei were labeled with DAPI (blue) (Scale bars: $50 \mu \mathrm{m}$ ).

68 | $P$ a g e

www.iiste.org 


\subsection{Valid Quality Control Tests}

3.2.1. Flow Cytometry Analysis of WJ-MSCs

Our data indicated that isolated WJ-MSCs were consistent with the immunophenotypic MSC characteristics mentioned in the literature[37] (data not shown).

\subsubsection{Gene Expression Profiles for WJ-MSCs}

The gene expression levels of four different WJ-MSCs were determined by real-time PCR (data not shown). The expression of transcripts for VIM, VCAM, THY1, NES, ICAM1, POU5F1, ZFP42, SOX2 and TERT were found positive. The cells were also found as positive for glyceraldehydes 3-phosphate dehydrogenase (GAPDH) as positive control. The expression of osteogenesis and adipogenesis (RUNX2), chondrogenesis, tenogenesis gene (BMP2) markers by WJ-MSCs were found positive.

\subsubsection{Sterility Tests}

WJ-MSCs from four donors were compliance with all quality control test values. As a result of these analyzes, WJ-MSCs were negative for endotoxin and mycoplasma tests. Sterility tests were performed for all stem cells and the results showed that all cells were aseptic (Table 1.).

Table 1: Results of Sterility Analysis for all WJ-MSCs donors

MSCs Endotoxin Mycoplasma Sterility/

\begin{tabular}{l|l|l|l}
\hline $\boldsymbol{W J}-\boldsymbol{M S C}-\boldsymbol{1}$ & Negative & Negative & Negative \\
\hline $\boldsymbol{W J}-\boldsymbol{M S C}-\boldsymbol{2}$ & Negative & Negative & Negative \\
\hline $\boldsymbol{W J}-\boldsymbol{M S C}-\mathbf{3}$ & Negative & Negative & Negative \\
\hline $\boldsymbol{W J}-\boldsymbol{M S C}-\boldsymbol{4}$ & Negative & Negative & Negative \\
\cline { 2 - 4 }
\end{tabular}

\subsection{Comparison of Assessments of Cell Viability with Flow Cytometry and Cell Analyzer}

The percentage of viability of WJ-MSCs from four different donors at $\mathrm{P} 4$ were generally proper with a mean of $92,48 \pm 0,487 \%$ and $90,76 \pm 1,116 \%$ as cell counting with cell analyzer (MUSE® Cell Analyzer, Millipore, Billerica, USA) and Flow Cytometryrespectively. Only WJ-MSC-3 has significant measurement difference between two different methods (Figure 4).

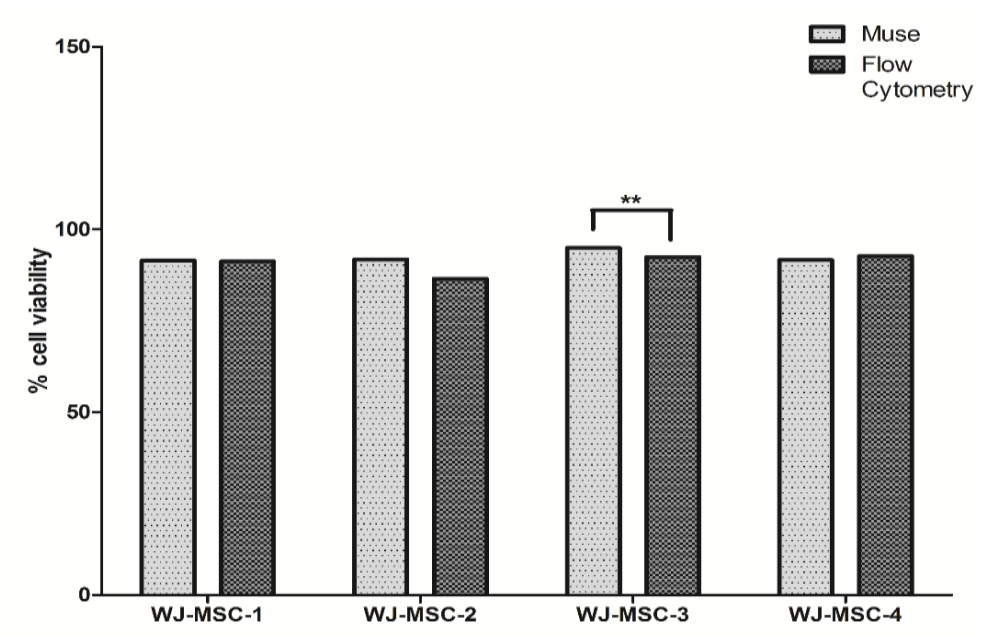

Figure 4: Annexin V cell viability assay by using Muse Cell Analyzer and Flow Cytometry. Only WJ-MSC-3 has significant cell viability difference with automated cell analyzer and Flow Cytometry using Annexin V. 


\subsection{Cellular Senescence and Telomerase Enzyme Activity Assessment}

SA-b-gal activity was found not at a critical level in any donor's cells for stem cell applications (Figure 5). Blue-dyed precipitate technique was performed to stain the cells with blue color which result from the cleavage of the chromogenic substrate 5-bromo-4-chloro-3-indolyl-beta-d-galactopyranoside (XGal) (Figure 6). According to our results, only WJ-MSC-3 showed a significant difference in RTA level from other WJ-MSCs $(p<0,001)$ (Figure 7). It is known that, there is a relation between cell senescence and telomerase activity on cultured cells. Thus we have found that telomerase activities were correlated with all different WJ-MSC donors.

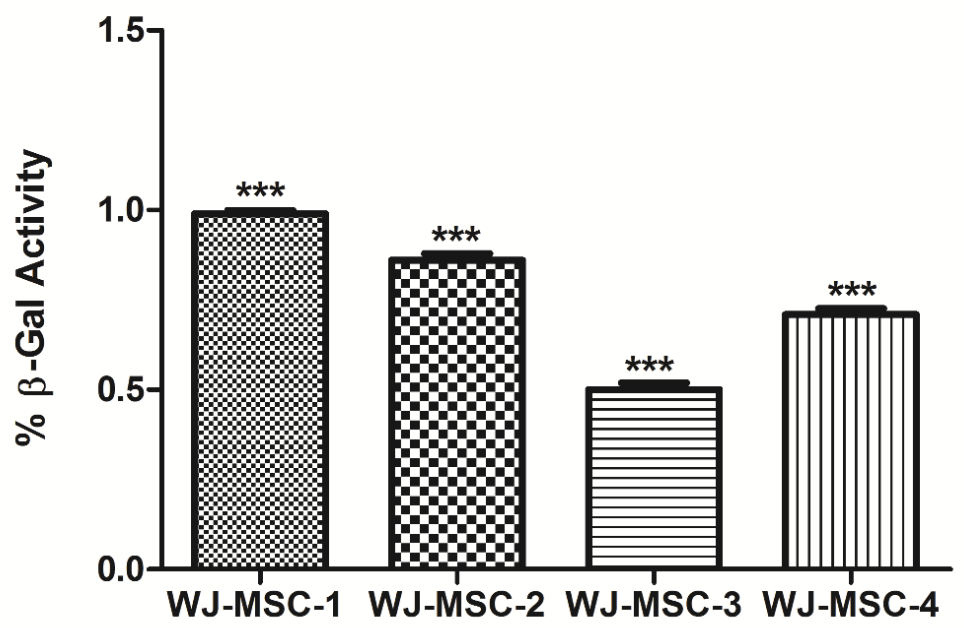

Figure 5: $\% \beta$-Gal Activity of four different WJ-MSCs donors

Senescence levels of our four donors were significantly different. One of the four WJ-MSCs (WJ-MSC3) has showed lower senescence level.
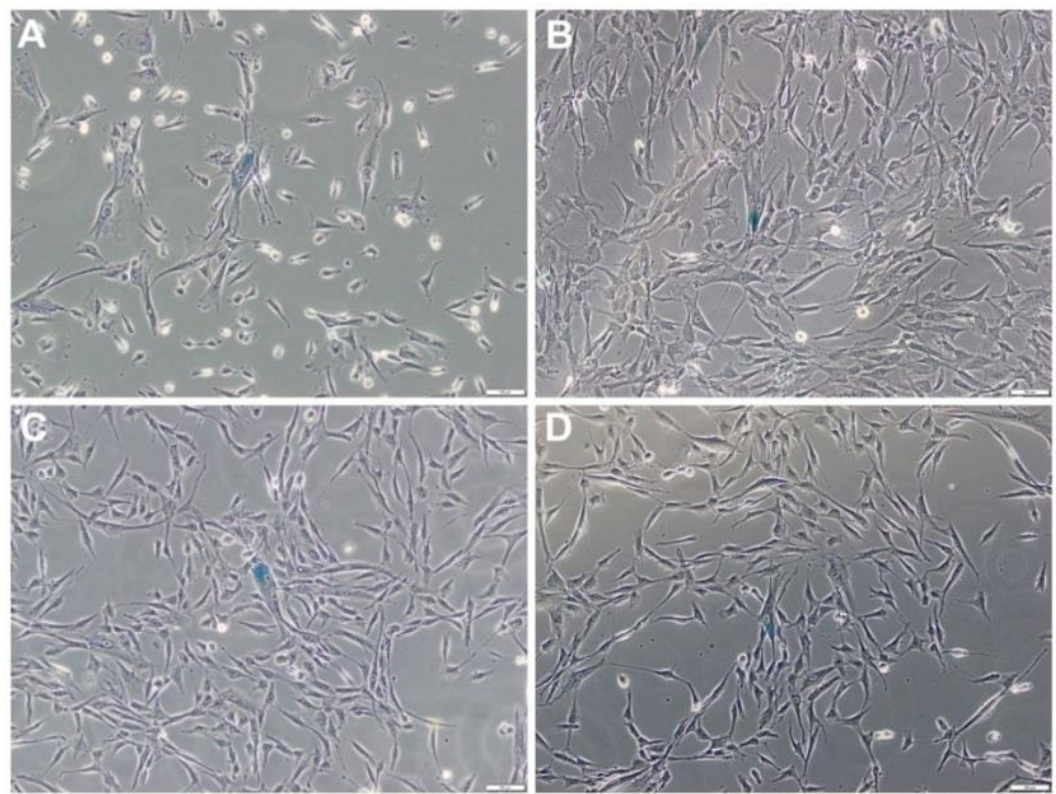

Figure 6: Senescent cell morphology (blue-stained cells) of 4 different donors at passage 4.

A) $W J-M S C-1$ B) WJ-MSC-2 C) WJ-MSC-3 D) WJ-MSC-4 


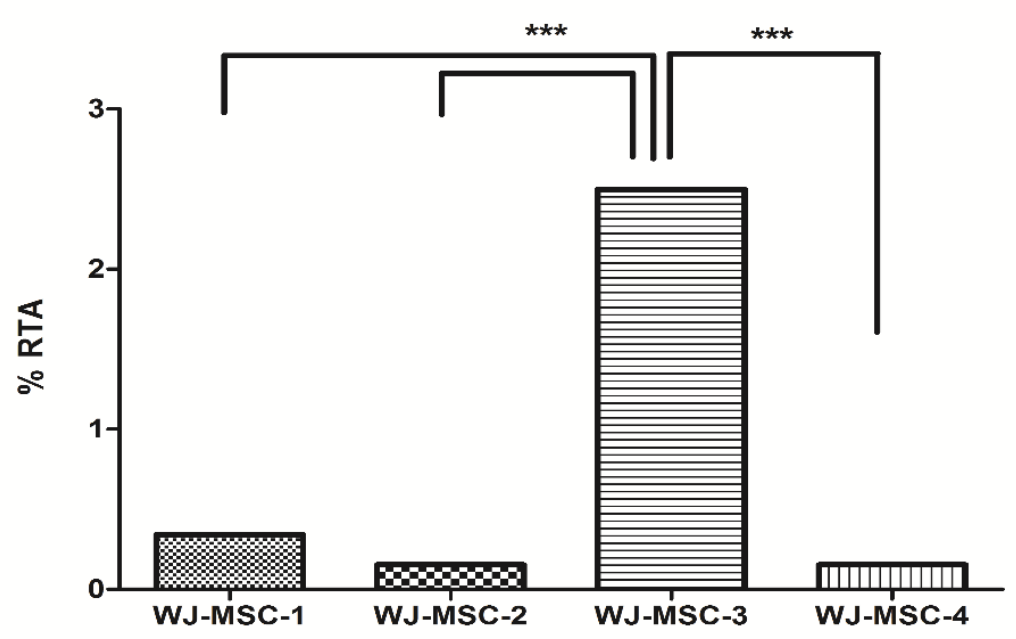

Figure 7: \% RTA value of four different WJ-MSCs donors

\section{Discussion}

The precision and accuracy of quality control tests strongly depend on the ability to generate highquality and functional cell based medicinal product with a high level of standardization. This study showed that, Annexin V assay which is performed for cell viability analysis and $\beta$-Gal assay which is used for determination of cell senescence level were important tests for GMP grade cell based medicinal products. As the result, only WJ-MSC-3 showed significant difference in two different viability methods using Annexin V, and WJ-MSC-3 was have higher telomerase activity against low senescence level. Most of the regulations from several regulatory institutions in developed countries for clinical cell-based therapy product manufacturing, accepted the same criteria for quality control tests. Valid QC tests generally include quality control parameters such as cell viability, endotoxin control, mycoplasma control, telomerase activity, gene expression, flow cytometry and microbiological analysis as international standards[38]. However Annexin V and $\beta$-Gal assays should be evaluate as "must" instead of "need".

Along with ISCT criteria, MSCs should have characteristic properties such as differentiation potential to chondrocytes, adipocytes, osteoblasts and also they should have specific cell surface markers [17].

Our results show that obtained WJ-MSCs from 4 donors can differentiate into chondrocytes, adipocytes, and osteoblasts as well as express MSC specific cell surface markers. Gene expression analyses have also supported these results via expression of stem cell specific genes.

As another QC analysis, telomerase activity test screens the telomerase level. Our results show that WJMSC-3 telomerase activity was significantly higher than others $(p<0,001)$ and this result is compatible with reference values [33]. Furthermore, other WJ-MSCs have showed no difference in telomerase activity among each other.

However, these tests are not enough to represent cell based medicinal products as "safe". Besides these cell characteristics, we have to be sure of the microbiological safety features of the cell products [1]. Along with endotoxin test; mycoplasma and microbiological sterility tests are necessary. In our study, all the microbiological test results were negative. Thus, WJ-MSCs, from 4 different donors, manufactured in our GMP grade laboratory are confirmed to be safe according to GMP grade cell based medicinal product regulations.

Characteristics of MSCs should be appropriate for cell-based medicinal treatment. Some of the significant changes in cell characteristics could be observed with senescence assays[39]. Cellular senescence may occur after a certain number of cell divisions as a result of decrease in telomerase activity that leads to inability of cell regeneration and stem cell function[40]. Our results show that senescence levels of our four donors were significantly different. However, one of the four WJ-MSCs (WJ-MSC-3) has showed lower senescence level from others. Literature showed that despite the enhanced cell viability at later passages, the expression of senescence level was significantly increased [41]. Enlarged and irregular cell morphology can be seen in in vitro cell culture in morphological assessment as well [42]. It is known that, donor age differences may influence proliferative 71 | $P$ a g e www.iiste.org 
characteristics and differentiation capacity of MSCs [34]. Age related differences are minimal in WJ derived MSCs samples as compared to other adult sources. MSCs harvested from the WJ are considered "young", much more proliferative, immunosuppressive, and even more therapeutically active than those isolated from "older", adult tissue sources [43, 44]. Our results together with the previously reported studies in the literature suggest that adult-derived mesenchymal stem cells will have more significant differences in senescence levels. Surprisingly, although RTA level of 3 of 4 different WJ-MSCs were very close to each other; telomerase activity of WJ-MSC-3 is significantly higher than others. With the present data in mind, telomerase activity and senescence levels may correlate and also may affect MSC quality in cell based therapy.

Viable cell counting is crucial for eukaryotic cells in research and clinical applications. There are several cell counting methods such as manual counting with hemocytometer, semi-automated and fullautomated techniques. Despite the manual and semi-automated methods, full automated methods have low error margin and allow analyzing early apoptotic and necrotic cells [45]. In our study, we used Annexin V method with two devices; Muse Cell Counter and Flow Cytometer. With Flow Cytometry, we also used PI dye which show late apoptotic and necrotic cells [46]. Although it is cheap and widely used, manual cell counting requires high expertise. Therefore, the viability and apoptotic, early apoptotic and necrotic cell ratio of cells is important, especially for quality (passage number, donor selection, isolation methods, used consumables, etc.) of cellular products in clinical cell based therapy. Based on our data, cell viability results of 4 WJ-MSCs were found higher than $90 \%(92,48 \pm 0,487 \%$ and $90,76 \pm 1,116 \%$ ) with two different methods according to cell based therapy standard. Also, we found the cells from 3 different donors have almost the same cell viability level, but only WJ-MSC-3 had significant cell viability difference between Muse Cell Counter and Flow Cytometer methods. It is essential to determine the percentages of cell viability for successful cell based medicinal products in clinical therapy.

MSCs can be isolated from various tissues and their functional properties and immunophenotypic characteristics are similar. Fetal MSCs generally perform better than adult MSCs [15]. However source-dependent differences in cell properties have emerged recently. Previously considered as a medical waste, umbilical cord seems to be a promising source of MSCs. Reports showing umbilical cord-derived MSCs being more primitive, more proliferative and more immunosuppressive [47]. In the senescence stage, MSCs proliferation and differentiation abilities are reduced, therefore senescence could restrain the use of MSCs in clinical trials[16].

Fetal stem cells (FSCs) are thought to be an intermediate link between embryonic stem cells (ESCs) and adult stem cells and they have enhanced plasticity, proliferation propensity, and higher expansion potential compared to adult MSCs [48, 49].

Thus, the findings of this study indicate that there are some differences, such as irregular telomerase activity and amount of senescent cell, which is related to stem cell source (adult or fetal). Therefore, Annexin V-based automated methods for determining the viability of cells may result in more reliable measures.

In the future, for increasing stem cell quality in GMP grade clinical trials, karyotype analysis, micronucleus detection and cell cycle tests among routine quality control tests will be crucial.

\section{Conclusion}

In this study, we suggest to add two techniques for QC analysis of MSCs in GMP grade cell based medicinal products. There are many of tests and parameters for quality control of GMP grade cell based medicinal products but some of them are not compulsory for regulations. Notably, donor patient's clinical history, age and genetic makeup strongly influence the length of cell expansion period and the quality of the obtained cells [15]. According to up scaled MSC production in GMP facility of cell based therapy products manufacturer, they could have increased risk of senescent cells and percentage of apoptotic cells. Thus $\beta$-Gal assay and Annexin V based automated methods must be performed within the QC tests as well, since it directly affects cell quality. Our results point that, the slight difference in senescence and cell viability results between 4 different donors of WJ-MSCs prove that the differences in adult sources will be different because WJ-MSCs are naive sources of MSCs. Therefore, we suggested that automated cell viability counting methods and $\beta$-Gal assay must be mandatory in order not to overlook this in scale up MSC production processes. 


\title{
Acknowledgements
}

The authors kindly thank Esra Albayrak, Elif Sozen and Busra Alper (Former staffs of Center for Regenerative Medicine and Stem Cell Manufacturing Liv Hospital, 34340, Besiktas, Istanbul, Turkey) and also research assistant Eda Sun (İstinye University Faculty of Medicine, 34010 Zeytinburnu, İstanbul Turkey) who supported to this study.

\author{
Abbreviations \\ MSCs: Mesenchymal stem cells \\ cGMP: current Good Manufacturing Practice \\ QC: Quality control \\ hMSCs: human Mesenchymal stem cells \\ GAPDH: glyceraldehydes 3-phosphate dehydrogenase \\ X-Gal: 5-bromo-4-chloro-3-indolyl-beta-d-galactopyranoside \\ WJ: Wharton Jelly \\ $\beta$-Gal or SA-b-gal: $\beta$-galactosidase \\ $\mathrm{Ct}$ : Cycle threshold
}

\section{Authors' contributions}

Experimental Design and Study: Koken GY, Oztel ON, Demir CS, Karaoz E; Literature research: Koken GY, Oztel ON, Demir CS, Karaoz E; Figure and table preparation: Koken GY, Demir CS, Oztel ON, Basaran IY; Manuscript writing and proofreading: Koken GY, Oztel ON, Karaoz E. All authors read and approved the final manuscript.

\section{Funding}

Not applicable.

\section{Availability of data and materials}

Not applicable.

\section{Ethics declarations}

\section{Ethics approval and consent to participate}

All procedures performed in studies involving human participants were in accordance with the ethical standards. Manufacturing and quality control tests of WJ-MSCs have been performed in a cGMP cell production facility; LivMedCell, authorized by the Ministry of Health of Turkey with the cGMP license rules.

\section{Consent for publication}

Not applicable.

\section{Conflict of Interest}

There is no conflict of interest.

\section{Competing interests}

The authors declare that they have no potential conflicts of interest.

\section{References}

[1] Lechanteur C, Briquet A, Giet O, Delloye O, Baudoux E, Beguin Y. (2016). Clinical-scale expansion of mesenchymal stromal cells: a large banking experience. J Transl Med 14 (1): 145.

[2] Pham PV, Vu NB, Pham VM, Truong NH, Pham TL, Dang LT, Nguyen TT, Bui AN, Phan NK. (2014). Good manufacturing practice-compliant isolation and culture of human umbilical cord blood-derived mesenchymal stem cells. J Transl Med , 12 (1): 56.

[3] English K, French A, Wood KJ. (2010). Mesenchymal stromal cells: facilitators of successful transplantation? Cell stem cell, 7 (4): 431-442. 
[4] Oh JY., Kim MK, Shin MS, Lee HJ, Ko JH, Wee WR, Lee JH. (2008). The anti-inflammatory and anti-angiogenic role of mesenchymal stem cells in corneal wound healing following chemical injury. Stem Cells , 26 (4): 1047-1055.

[5] Smith JR, Pfeifer K, Petry F, Powell N, Delzeit J, Weiss ML. (2016). Standardizing umbilical cord mesenchymal stromal cells for translation to clinical use: selection of GMP-compliant medium and a simplified isolation method. Stem Cells Int.

[6] Kalaszczynska I. and Ferdyn K. (2015). Wharton's jelly derived mesenchymal stem cells: future of regenerative medicine? Recent findings and clinical significance. Biomed Res Int.

[7] McGuirk JP, Smith JR, Divine CL, Zuniga M, Weiss ML. (2015). Wharton's jelly-derived mesenchymal stromal cells as a promising cellular therapeutic strategy for the management of graft-versus-host disease. Pharmaceuticals, 8(2): 196-220.

[8] Deuse T, Stubbendorff M, Tang-Quan K, Phillips N, Kay MA, Eiermann T, Phan TT, Volk HD. (2011). Reichenspurner H, Robbins RC, Schrepfer S. Immunogenicity and immunomodulatory properties of umbilical cord lining mesenchymal stem cells. Cell Transplant, 20(5): 655-667.

[9] Zeddou M, Briquet A, Relic B, Josse C, Malaise MG, Gothot A, Lechanteur C, Beguin Y. (2010). The umbilical cord matrix is a better source of mesenchymal stem cells (MSC) than the umbilical cord blood. Cell Biol Int, 34(7): 693-701.

[10] Karaöz E, İnci Ç. (2016). Umbilical Cord Tissue and Wharton's Jelly Mesenchymal Stem Cells Properties and Therapeutic Potentials. In Perinatal Tissue-Derived Stem Cells Humana Press, Cham., 41-63.

[11] Lila N, Carpentier A, Amrein C, Khalil-Daher I, Dausset J, Carosella ED. (2000). Implication of HLA-G molecule in heart-graft acceptance. Lancet; 355(9221): 2138.

[12] Lv YT1, Zhang Y, Liu M, Qiuwaxi JN, Ashwood P, Cho SC, Huan Y, Ge RC, Chen XW, Wang ZJ, et al. (2013). Transplantation of human cord blood mononuclear cells and umbilical cordderived mesenchymal stem cells in autism. J Transl Med, 11 (1): 196.

[13] 13. Dongmei H, Jing L, Mei X, Ling Z, Hongmin Y, Zhidong W, Li D, Zikuan G, Hengxiang W. (2011). Clinical analysis of the treatment of spinocerebellar ataxia and multiple system atrophy-cerebellar type with umbilical cord mesenchymal stromal cells. Cytotherapy, 13(8): 913-917.

[14] Jin JL, Liu Z, Lu ZJ, Guan DN, Wang C, Chen ZB, Zhang J, Zhang WY, Wu JY, Xu Y. (2013). Safety and efficacy of umbilical cord mesenchymal stem cell therapy in hereditary spinocerebellar ataxia. Curr Neurovasc Res., 10 (1): 11-20.

[15] Scheers I, Lombard C, Paganelli M, Campard D, Najimi M, Gala JL, Decottignies A, Sokal E.( 2013). Human umbilical cord matrix stem cells maintain multilineage differentiation abilities and do not transform during long-term culture. PLoS One ; 8 (8): e71374.

[16] Dominici MLBK, Le Blanc K, Mueller I, Slaper-Cortenbach I, Marini F, Krause D, Deans R, Keating A, Prockop Dj, Horwitz E. (2006). Minimal criteria for defining multipotent mesenchymal stromal cells. The International Society for Cellular Therapy position statement. Cytotherapy, 8(4): 315-317. 
[17] Bourin P, Bunnell BA, Casteilla L, Dominici M, Katz AJ, March KL, Redl H, Rubin JP, Yoshimura K, Gimble JM. (2013). Stromal cells from the adipose tissue-derived stromal vascular fraction and culture expanded adipose tissue-derived stromal/stem cells: a joint statement of the International Federation for Adipose Therapeutics and Science (IFATS) and the International Society for Cellular Therapy (ISCT). Cytotherapy, 15(6): 641-648.

[18] Di Iorio E, Ferrari S, Fasolo A, Böhm E, Ponzin D, Barbaro V. (2010). Techniques for culture and assessment of limbal stem cell grafts. Ocul Surf, 8(3): 146-153.

[19] Giancola R, Bonfini T, Iacone A. (2012). Cell therapy: cGMP facilities and manufacturing. Muscles Ligaments Tendons J, 2(3): 243.

[20] Yuan, BZ. (2015). Establishing a quality control system for stem cell-based medicinal products in China. Tissue Eng Part A, 21(23-24): 2783-2790.

[21] Turinetto V, Vitale E, Giachino C. (2016). Senescence in human mesenchymal stem cells: functional changes and implications in stem cell-based therapy. Int J Mol Sci, 17(7): 1164.

[22] Danisovic L., Oravcova L, Krajciova L, Varchulova Novakova Z, Bohac M, Varga I, Vojtassak J.( 2017). Effect of long-term culture on the biological and morphological characteristics of human adipose tissue-derived stem cells. J Physiol Pharmacol, 68(1): 149-158.

[23] Zhu W, Chen J, Cong X, Hu S, Chen X. (2006). Hypoxia and serum deprivation-induced apoptosis in mesenchymal stem cells. Stem Cells, 24(2): 416-425.

[24] Anthony RS, McKelvie ND, Cunningham AJ, Craig JIO, Rogers SY, Parker AC. (1998). Flow cytometry using annexin $\mathrm{V}$ can detect early apoptosis in peripheral blood stem cell harvests from patients with leukaemia and lymphoma. Bone Marrow Transplant, 21(5): 441.

[25] Casaroli-Marano RP, Tabera J, Vilarrodona A, Trias, E. (2014). Regulatory issues in cell-based therapy for clinical purposes. Dev Ophthalmol, 53: 189-200.

[26] Kolkundkar U, Gottipamula S, Majumdar A. (2014). Cell therapy manufacturing and quality control: current process and regulatory challenges. J Stem Cell Res Ther, 4 (9): 230.

[27] von Tigerstrom B. (2011). The Food and Drug Administration, regenerative sciences, and the regulation of autologous stem cell therapies. Food Drug Law J, 66: 479.

[28] Fink DW. (2009). FDA regulation of stem cell-based products. Science; 324 (5935): $1662-$ 1663.

[29] Gouda AM, Abdelazeem AH, Omar HA, Abdalla AN, Abourehab MA, Ali HI. (2017). Pyrrolizines: Design, synthesis, anticancer evaluation and investigation of the potential mechanism of action. Bioorg Med Chem; 25(20): 5637-5651.

[30] Yuksel S, Guleç MA, Gultekin MZ, Adanır O, Caglar A, Beytemur O, Onur Küçükyıldırım B, Avcı A, Subaşı C, İnci Ç et al. (2016). Comparison of the early period effects of bone marrowderived mesenchymal stem cells and platelet-rich plasma on the Achilles tendon ruptures in rats. Connect Tissue Res, 57(5): 360-373.

[31] Lech W, Figiel-Dabrowska A, Sarnowska A, Drela K, Obtulowicz P, Noszczyk BH, Buzanska L, Domanska-Janik K. (2016). Phenotypic, functional, and safety control at preimplantation phase of MSC-based therapy. Stem Cells Int . 
[32] Karaöz E, Doğan BN, Aksoy A, Gacar G, Akyüz S, Ayhan S, Genç ZS, Yürüker S, Duruksu G, Demircan PC, et al. (2010). Isolation and in vitro characterisation of dental pulp stem cells from natal teeth. Histochem Cell Biol, 133 (1). 95.

[33] Karaöz E, Okçu A, Gacar G, Sağlam Ö, Yürüker S, Kenar H. A. (2011). comprehensive characterization study of human bone marrow mscs with an emphasis on molecular and ultrastructural properties. J Cell Physiol, 226(5): 1367-1382.

[34] Fazzina R, Mariotti A, Procoli A, Fioravanti D, Iudicone P, Scambia G, Pierelli L, Bonanno G. (2015). A new standardized clinical-grade protocol for banking human umbilical cord tissue cells. Transfusion, 55(12): 2864-2873.

[35] Karaoz E, Genc ZS, Demircan PÇ, Aksoy A, Duruksu G. (2010). Protection of rat pancreatic islet function and viability by coculture with rat bone marrow-derived mesenchymal stem cells. Cell Death Dis, 1(4): 36.

[36] Karaoz E, Aksoy A, Ayhan S, Sarıboyacı AE, Kaymaz F, Kasap M. (2009). Characterization of mesenchymal stem cells from rat bone marrow: ultrastructural properties, differentiation potential and immunophenotypic markers. Histochem Cell Biol, 132(5): 533.

[37] Horwitz EM, Le Blanc K, Dominici M, Mueller I, Slaper-Cortenbach I, Marini FC, Deans RJ, Krause DS, Keating A. (2005). Clarification of the nomenclature for MSC: International Society for Cellular Therapy. Cytotherapy, 7(5): 393-395.

[38] Rustichelli D, Castiglia S, Gunetti M, Mareschi K, Signorino E, Muraro M, Castello L, Sanavio F, Leone M, Ferrero I, et al. (2013). Validation of analytical methods in compliance with good manufacturing practice: a practical approach. J Transl Med, 11(1): 197.

[39] Wagner W, Horn P, Castoldi M, Diehlmann A, Bork S, Saffrich R, Benes V, Blake J, Pfister S, Eckstein V, et al. (2008). Replicative senescence of mesenchymal stem cells: a continuous and organized process. PloS one, 3(5): 2213.

[40] 40. Flores I. and Blasco MA. The role of telomeres and telomerase in stem cell aging. (2010). FEBS Lett; 584 (17): 3826-3830.

[41] Ridzuan N, Al Abbar A, Yip WK, Maqbool M, Ramasamy R. (2016). Characterization and expression of senescence marker in prolonged passages of rat bone marrow-derived mesenchymal stem cells. Stem Cells Int.

[42] von Bahr L, Sundberg B, Lönnies L, Sander B, Karbach H, Hägglund H, Ljungman P, Gustafsson B, Karlsson H, Le Blanc K et al. (2012). Long-term complications, immunologic effects, and role of passage for outcome in mesenchymal stromal cell therapy. Biol Blood Marrow Transplant, 18(4): 557-564.

[43] Kim DW, Staples M, Shinozuka K, Pantcheva P, Kang SD, Borlongan CV. (2013). Wharton's jelly-derived mesenchymal stem cells: phenotypic characterization and optimizing their therapeutic potential for clinical applications. Int J Mol Sci, 14(6): 11692-11712.

[44] Prasanna SJ, Gopalakrishnan D, Shankar SR, Vasandan AB. (2010). Pro-inflammatory cytokines, IFN $\gamma$ and TNF $\alpha$, influence immune properties of human bone marrow and Wharton jelly mesenchymal stem cells differentially. PloS one , 5(2): e9016.

[45] Cadena-Herrera D, Esparza-De Lara JE, Ramírez-Ibañez ND, López-Morales CA, Pérez NO, Flores-Ortiz LF, Medina-Rivero E. (2015). Validation of three viable-cell counting methods: manual, semi-automated, and automated. Biotechnol Rep (Amst). 7: 9-16. 
[46] Rieger AM, Nelson KL, Konowalchuk JD, Barreda DR. (2011). Modified annexin $\mathrm{V} /$ propidium iodide apoptosis assay for accurate assessment of cell death. J Vis Exp; 50.

[47] El Omar R, Beroud J, Stoltz JF, Menu P, Velot E, Decot V. (2014). Umbilical cord mesenchymal stem cells: the new gold standard for mesenchymal stem cell-based therapies? Tissue Eng Part B Rev, 20(5): 523-544.

[48] Mafi R, Hindocha S, Mafi P, Griffin M, Khan WS. (2011). Suppl 2: Sources of Adult Mesenchymal Stem Cells Applicable for Musculoskeletal Applications-A Systematic Review of the Literature. Open Orthop J; 5: 242.

[49] Brady K, Dickinson SC, Guillot PV, Polak J, Blom AW, Kafienah W, Hollander AP. (2013). Human fetal and adult bone marrow-derived mesenchymal stem cells use different signaling pathways for the initiation of chondrogenesis. Stem Cells Dev, 23(5): 541-554. 